\title{
Unemployment and prostate cancer mortality in the OECD, 1990-2009
}

\author{
Mahiben Maruthappu ${ }^{1 \dagger}$, Johnathan Watkins ${ }^{2 \dagger}$, Abigail Taylor ${ }^{3}$, Callum Williams ${ }^{4}$, Raghib Ali $^{5,6}$, Thomas Zeltner $^{7,8}$ and \\ Rifat Atun ${ }^{1,9}$ \\ ${ }^{1}$ Faculty of Medicine, Imperial College London, London SW7 2AZ, UK \\ ${ }^{2}$ Institute for Mathematical and Molecular Biomedicine, King's College London, London SE1 1UL, UK \\ ${ }^{3}$ Medical Sciences Division, University of Oxford, OX1 2JD, UK \\ ${ }^{4}$ The Economist, 25 St James's Street, London SW1A 1HG, UK \\ ${ }^{5}$ Cancer Epidemiology Unit, University of Oxford, Oxford OX3 7LF, UK \\ ${ }^{6}$ Faculty of Medicine and Health Sciences, United Arab Emirates University, PO Box 17666, United Arab Emirates \\ ${ }^{7}$ Special Envoy for Financing to the Director General of the World Health Organization (WHO), 1211 Geneva 27, Switzerland \\ 8University of Bern, Bern CH 3011, Switzerland \\ ${ }^{9}$ Harvard School of Public Health, Harvard University, MA 02115, USA \\ †Joint first authors
}

Correspondence to: Mahiben Maruthappu. Email: maruthappu@post.harvard.edu

\section{Abstract}

The global economic downturn has been associated with increased unemployment in many countries. Insights into the impact of unemployment on specific health conditions remain limited. We determined the association between unemployment and prostate cancer mortality in members of the Organisation for Economic Co-operation and Development (OECD). We used multivariate regression analysis to assess the association between changes in unemployment and prostate cancer mortality in OECD member states between 1990 and 2009 . Country-specific differences in healthcare infrastructure, population structure, and population size were controlled for and lag analyses conducted. Several robustness checks were also performed. Time trend analyses were used to predict the number of excess deaths from prostate cancer following the 2008 global recession. Between 1990 and 2009, a 1\% rise in unemployment was associated with an increase in prostate cancer mortality. Lag analysis showed a continued increase in mortality years after unemployment rises. The association between unemployment and

ecancer 2015, 9:538 DOI: 10.3332/ecancer.2015.538

Copyright: (c) the authors; licensee ecancermedicalscience. This is an Open Access article distributed under the terms of the Creative Commons Attribution License (http://creativecommons.org/licenses/by/3.0), which permits unrestricted use, distribution, and reproduction in any medium, provided the original work is properly cited. 
prostate cancer mortality remained significant in robustness checks with 46 controls. Eight of the 21 OECD countries for which a time trend analysis was conducted, exhibited an estimated excess of prostate cancer deaths in at least one of 2008, 2009, or 2010, based on 2000-2007 trends. Rises in unemployment are associated with significant increases in prostate cancer mortality. Initiatives that bolster employment may help to minimise prostate cancer mortality during times of economic hardship.

Keywords: economic crisis, health economics, mortality, prostate cancer, unemployment

\section{Introduction}

Prostate cancer is the most commonly occurring cancer among men in many OECD countries, accounting for around one in six of all male cancer mortality in 2009 (124 deaths per 100,000 males) [1]. The reported incidence of prostate cancer is steadily increasing in almost all countries, largely because of the increased use of prostate-specific antigen (PSA) testing as an indicator [1], even though we still have relatively little understanding of its aetiology $[2,3]$. Higher socioeconomic status (SES) is associated with higher incidence of prostate cancer diagnosis but with better outcomes $[4,5]$. A number of studies have documented associations between lower SES and increased prostate cancer mortality, with the risk of dying increased two-fold in more deprived groups [6-8].

The global economic downturn has led to a number of OECD governments introducing economic policies that attempt to reduce budget deficits [9]. These measures, composed of tax rises and cuts in public spending, have often exacerbated already high unemployment levels [10, 11]. In Ireland, Spain, and the United States, unemployment rates in 2006 before the economic crisis were 4.4, 8.5, and 4.6, respectively. At the height of the economic crisis in 2009, these had reached 12.0, 18.0, and 9.3 respectively [12].

The economic recession has been associated with poorer health outcomes including a rise in suicide rates [11, 13, 14], increased infectious-disease incidence and mortality [10, 15-18], and decreased health-related quality of life [19]. On an individual level, unemployment, in particular, has been observed to correlate with increased mortality [20, 21]. Whilst the literature focuses on all-cause mortality as well as mental health and behaviour-related causes such as suicide, there is a lack of detailed analysis on the effect of unemployment on specific diseases. The effects of the recent economic downturn therefore raise the question of how unemployment changes, within and outside of an economic crisis, affect condition-specific health outcomes.

We sought to analyse the relationship between prostate cancer mortality and unemployment in the OECD countries between 1990 and 2009 , hypothesising that increased unemployment rates would be associated with increased prostate cancer deaths because of various factors, including reduced access to health care.

\section{Methods}

\section{Data collection}

In an effort to reduce inter-country heterogeneity with respect to the reporting of variables such as unemployment and cancer mortality, we confined our analysis to OECD economies, which generally have agreed criteria for reporting population level variables. Data on prostate cancer mortality (age-standardised deaths per 100,000 people; ASDR) in each OECD country between 1990 and 2009 were obtained from the World Health Organisation (WHO) mortality database [22]. A prostate cancer death is identified as having the derived underlying cause code ICD-10 C61 or ICD-9 185. The quality of the data had been evaluated by the WHO [23]. Chile, Estonia, Israel, and Slovenia were excluded from the analysis because they joined the OECD after 2009. Unemployment, defined as the percentage of the labour force that is without work but available and seeking employment (World Bank data code: SL.UEM.TOTL.ZS), were obtained from the World Bank Development Indicators and Global Development Finance 2013 edition [12] (Table 1). Data used in the robustness checks were also obtained from the World Bank [12]. 
Table 1. OECD countries, unemployment in 2009 , and the average prostate cancer mortality rate between 1990-2009.

\begin{tabular}{|c|c|c|}
\hline Country & $\begin{array}{l}\text { Unemployment } \% \text { of total } \\
\text { labour force, } 2009\end{array}$ & $\begin{array}{l}\text { Average prostate cancer mortality } \\
\text { (ASDR per 100,000), 1990-2009 }\end{array}$ \\
\hline Australia & 5.6 & 15.315 \\
\hline Austria & 4.8 & 15.530 \\
\hline Belgium & 7.9 & 13.225 \\
\hline Canada & 8.3 & 14.055 \\
\hline Czech Republic & 6.7 & 15.905 \\
\hline Denmark & 6.0 & 19.235 \\
\hline Finland & 8.2 & 16.665 \\
\hline France & 9.1 & 14.995 \\
\hline Germany & 7.7 & 14.715 \\
\hline Greece & 9.5 & 9.790 \\
\hline Hungary & 10.0 & 15.115 \\
\hline Iceland & 7.2 & 19.360 \\
\hline Ireland & 10.0 & 17.335 \\
\hline Italy & 7.8 & 9.440 \\
\hline Japan & 5.0 & 5.020 \\
\hline Republic of Korea & 3.6 & 2.875 \\
\hline Luxembourg & 5.1 & 13.825 \\
\hline Mexico & 5.2 & 10.740 \\
\hline Netherlands & 3.4 & 17.180 \\
\hline New Zealand & 6.1 & 17.595 \\
\hline Norway & 3.2 & 21.640 \\
\hline Poland & 8.2 & 10.695 \\
\hline Portugal & 9.5 & 12.680 \\
\hline Slovak Republic & 12.1 & 15.400 \\
\hline Spain & 18.0 & 12.170 \\
\hline Sweden & 8.3 & 20.820 \\
\hline Switzerland & 4.1 & 17.835 \\
\hline Turkey & 14.0 & - \\
\hline United Kingdom & 7.7 & 15.650 \\
\hline United States & 9.3 & 13.635 \\
\hline
\end{tabular}

ASDR, Age-standardised death rate

Source: World Bank Development Indicators 2013

\section{Fixed-effects regression analysis}

Multivariate regression analysis was used to assess the relationship between prostate cancer mortality (dependent variable) and unemployment (independent variable). To control for national variations in health care infrastructure and ensure that results were not driven by extreme observations for certain countries, a fixed-effects approach was used in the regression models, including 30 dummy 
variables for the 30 countries in the dataset. This allowed the models to evaluate mortality changes within individual countries while holding constant time-invariant differences (such as higher predispositions to prostate cancer as well as political, cultural, and structural differences) between countries. In effect, this conservative modelling approach made the data more comparable. To control for demographic structure, total population size and percentage of the population aged over 65 years and less than 15 years were incorporated into the model. The Cook-Weisberg test [24] was used to assess for heteroskedasticity (where sub-samples have different distributions) in the data. With the data testing positive for heteroskedasticity, robust standard errors were included in the regression models, this accounted for in part, variations in how unemployment was measured between countries. This methodology has been widely used in similar health-economic studies, and is regarded as a statistically robust and conservative approach [25-28].

Our basic linear fixed effects statistical model was as follows:

$$
\mathrm{H}_{i, t}-\mathrm{H}_{i, 0}=\alpha+\left(\mathrm{U}_{i, t}-\mathrm{U}_{i, 0}\right) \beta+\eta t+\varepsilon_{i, t},
$$

where $i$ is country and $t$ is year; $\mathrm{H}$ is the health metric (prostate cancer mortality); $\mathrm{U}$ is the measure of unemployment; $\alpha$ represents the population structure of the country being analysed, $\eta$ is a dummy variable for each country included in the regression model, and $\varepsilon$ is the error term.

We conducted one, two, three, four, and five-year time-lag multivariate analyses to quantify the long-term effects of changes in unemployment on prostate cancer mortality. Several robustness checks were also conducted; these are detailed in the results section.

\section{Time trend analysis}

From the original 30 OECD countries included in the study, we required countries included in our time trend analysis to have at a minimum a complete consecutive data from 2002 to 2010, inclusive. As a consequence of this inclusion criterion, we excluded Australia, Belgium, Iceland, Ireland, Italy, New Zealand, Portugal, Turkey, and Greece, leaving 21 countries. We used the years before 2007 inclusive as an observation base and fitted a linear Poisson regression model (to ensure no negative rates for decreasing trends) or a nonlinear model (for ascending trends) to these data in order to project mortality rates for the years 2008, 2009, and 2010 [29]. The geometric mean of the annual percentage change in observation-base mortality rates was used to determine whether a trend was either positive or negative. These forecasted mortality rates were then compared with the observed rates for 2008-2010 and rate ratios calculated.

Stata SE version 12 (Stata Corporation, Texas, USA) and R version 3.1.2 were used for the analysis.

\section{Results}

Figure 1 shows the results of five regression models on OECD countries in the period 1990-2009. The results displayed are adjusted for population size, demographic structure, and variations in infrastructure. The results show that a $1 \%$ increase in unemployment is associated with a statistically significant increase in prostate cancer mortality (coefficient $=0.2193,95 \%$ confidence interval $(\mathrm{Cl}): 0.1611-0.275$, $p<0.0001)$.

\section{Lag analysis}

Further analysis was performed to investigate whether this association lasted in the longer term. The results for one, two, three, four, and five years following a $1 \%$ rise in unemployment in an OECD country during the period show that prostate cancer mortality continued to increase at one year after (coefficient $=0.2475,95 \% \mathrm{Cl}: 0.1885-0.3066, p<0.0001$ ), and remained high in the subsequent years (two year coefficient $=0.2435,95 \%$ Cl: $0.1869-0.3001, p<0.0001$; three-year coefficient $=0.2380,95 \%$ Cl: $0.1803-0.2958, p<0.0001$; four year coefficient $=0.2154,95 \% \mathrm{Cl}: 0.1582-0.2726, p<0.0001$; five year coefficient $=0.1869,95 \% \mathrm{Cl}=0.1247-0.2492, p<0.0001)($ Figure 1 ). 


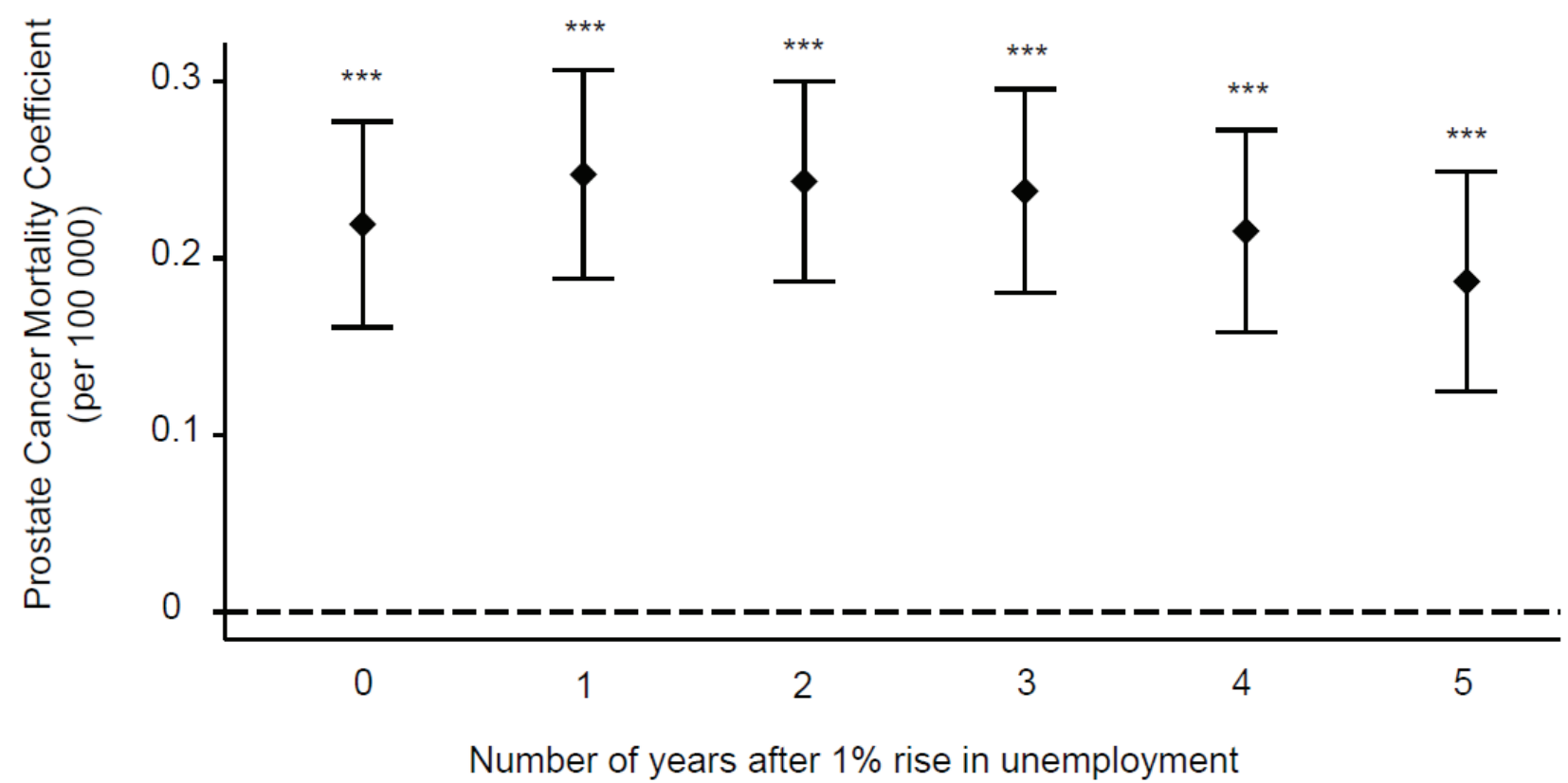

Figure 1. Time-lag analysis of unemployment and prostate cancer mortality. Multivariate regression analysis was used to access the relationship between prostate cancer mortality and increased unemployment. The prostate cancer mortality coefficients and their corresponding $\mathrm{Cl}$ are displayed for the time frame of up to five years after a $1 \%$ rise in unemployment. ${ }^{* *} p<0.001$.

\section{Robustness checks}

In order to control for confounding factors, the analysis was re-run with multiple economic, infrastructure, and health care spending controls in addition to the original controls (population size, proportion of population over 65 and under 15 , and with 30 country controls). To control for economic influences, variables for changes in gross deomestic product (GDP) per capita, inflation, and interest rates were used. To control for infrastructure the effects of changes in infrastructure, controls for urbanisation, access to water, and mean calorie intake were used. Number of physicians per 100,000 and number of hospital beds per 100,000 were taken as controls of hospital resources. Finally, we re-ran the analysis controlling for out-of-pocket spending per capita. The association between a $1 \%$ rise in unemployment and increased prostate cancer mortality remained statistically significant for all individual robustness checks (Table 2), and when the analysis was run with all 46 controls simultaneously (coefficient $=0.1276,95 \% \mathrm{Cl}: 0.0032-0.2519, p=0.0445$ ).

\section{Time trend analysis}

To examine whether the spike in unemployment that resulted from the Great Recession of 2008 had any effect on prostate cancer mortality rates, we conducted a time trend analysis on 21 OECD countries. Among these countries, Austria, Canada, Germany, and Hungary exhibited a significantly higher prostate cancer death rate in 2008, 2009, and 2010 as compared to what would have been expected based upon rates in 2000-2007 with 2008 being the year at which the greatest deviation was observed for Austria (rate ratio = 1.1066, 95\% $\mathrm{Cl}: 1.0742-1.141, p<0.0001$; excess deaths $=114,95 \% \mathrm{Cl}: 82-146)$, and 2010 for the other three (Canada: rate ratio $=1.095,95 \% \mathrm{Cl}$ : $1.0765-1.1142, p<0.0001$; excess deaths $=333,95 \% \mathrm{Cl}: 272-393$; Germany: rate ratio $=1.0939,95 \% \mathrm{Cl}: 1.0739-1.1147, p<0.0001$; 
excess deaths $=1,088,95 \% \mathrm{Cl}: 872-1304 ;$ Hungary: rate ratio $=1.2373,95 \% \mathrm{Cl}: 1.1712-1.3112, p<0.0001 ;$ excess deaths $=232,95 \%$ Cl: 177-287) (Figure 2). The Netherlands, Spain, Switzerland, and the United States of America only exhibited this significantly higher deviation from the expected in 2010 (The Netherlands: rate ratio $=1.0389,95 \% \mathrm{Cl}: 1.0177-1.061, p=0.00035$; excess deaths $=97$, 95\% Cl: 45-149; Spain: rate ratio $=1.0675,95 \%$ Cl: 1.0435-1.0927, $p<0.0001$; excess deaths = 372, 95\% Cl: 245-498; Switzerland: rate ratio $=1.1103,95 \% \mathrm{Cl}: 1.0851-1.1367, p<0.0001$; excess deaths $=141,95 \% \mathrm{Cl}: 111-171 ;$ United States: rate ratio $=1.0417,95 \%$ Cl: $1.0259-1.0579, p<0.0001$; excess deaths $=1142,95 \% \mathrm{Cl}: 720-1564)$ (Figure 2). Many of the other OECD countries had trends in which the observed rates were higher than the expected rates; however, these differences were not significant. In contrast to the decreasing prostate cancer mortality rates seen in most countries, the Republic of Korea and Poland exhibited an increase and a relatively stable annual rate of prostate cancer deaths between 2000 and 2010. However, the observed mortality rates for these two countries did not differ significantly from the expected rates despite the fact that both countries experienced a sharp upturn in unemployment from 2008 onwards.

\section{Discussion}

This study has demonstrated that increased unemployment is associated with a significant rise in prostate cancer mortality in OECD countries. This association continued for at least five years after a $1 \%$ rise in unemployment, even when controlling for economic factors, infrastructure, hospital resources, and health care spending. Because of the inclusion of such a large number of control variables, we were losing on degrees of freedom and had to reduce the sample size. Thus our results represented a highly conservative estimate of the impact of unemployment on prostate cancer mortality. Our findings were substantiated through a time trend analysis conducted on a per-country basis and examining the effect of the Great Recession of 2008 on prostate cancer mortality rates.

Table 2. Robustness checks.

\begin{tabular}{|c|c|c|c|c|c|c|}
\hline Robustness check & Controls used in multiple regression & $\begin{array}{l}\text { Total number } \\
\text { of controls in } \\
\text { regression }\end{array}$ & Coefficient & $p$ Value & $\begin{array}{l}\text { Lower } \\
\text { confidence } \\
\text { interval }\end{array}$ & $\begin{array}{l}\text { Upper } \\
\text { confidence } \\
\text { interval }\end{array}$ \\
\hline Economic controls & $\begin{array}{l}\text { Original analysis controls and changes in GDP per } \\
\text { capita, inflation, interest rates }\end{array}$ & 39 & 0.1322 & 0.0004 & 0.0595 & 0.2049 \\
\hline $\begin{array}{l}\text { Infrastructure } \\
\text { controls }\end{array}$ & $\begin{array}{l}\text { Original analysis controls and urbanisation, access to } \\
\text { water, nutrition (mean calorie intake) }\end{array}$ & 39 & 0.1459 & 0.0000 & 0.0892 & 0.2027 \\
\hline $\begin{array}{l}\text { Economic and } \\
\text { infrastructure } \\
\text { controls }\end{array}$ & $\begin{array}{l}\text { Original analysis controls and urbanisation, access } \\
\text { to water, nutrition (mean calorie intake), changes in } \\
\text { GDP per capita, inflation, interest rates }\end{array}$ & 42 & 0.0855 & 0.0095 & 0.0210 & 0.1499 \\
\hline $\begin{array}{l}\text { Hospital resource } \\
\text { controls }\end{array}$ & $\begin{array}{l}\text { Original analysis controls and number of physicians } \\
\text { per } 100000 \text {; number of hospital beds per } 100000\end{array}$ & 38 & 0.2200 & 0.0000 & 0.1474 & 0.2925 \\
\hline $\begin{array}{l}\text { Out of pocket } \\
\text { spending control }\end{array}$ & $\begin{array}{l}\text { Original analysis controls and out of pocket spending } \\
\text { per capita }\end{array}$ & 37 & 0.1344 & 0.0002 & 0.0644 & 0.2043 \\
\hline $\begin{array}{l}\text { Public spending on } \\
\text { health care control }\end{array}$ & $\begin{array}{l}\text { Original analysis controls and public spending on } \\
\text { health care }\end{array}$ & 37 & 0.1244 & 0.0004 & 0.0560 & 0.1927 \\
\hline $\begin{array}{l}\text { All abovementioned } \\
\text { controls }\end{array}$ & $\begin{array}{l}\text { Original analysis controls and urbanisation, access } \\
\text { to water, nutrition (mean calorie intake), changes in } \\
\text { GDP per capita, inflation, interest rates, number of } \\
\text { physicians per } 100,000 \text {; number of hospital beds per } \\
100,000 \text {; out of pocket spending, and public spending } \\
\text { on health care }\end{array}$ & 46 & 0.1276 & 0.0445 & 0.0032 & 0.2519 \\
\hline
\end{tabular}




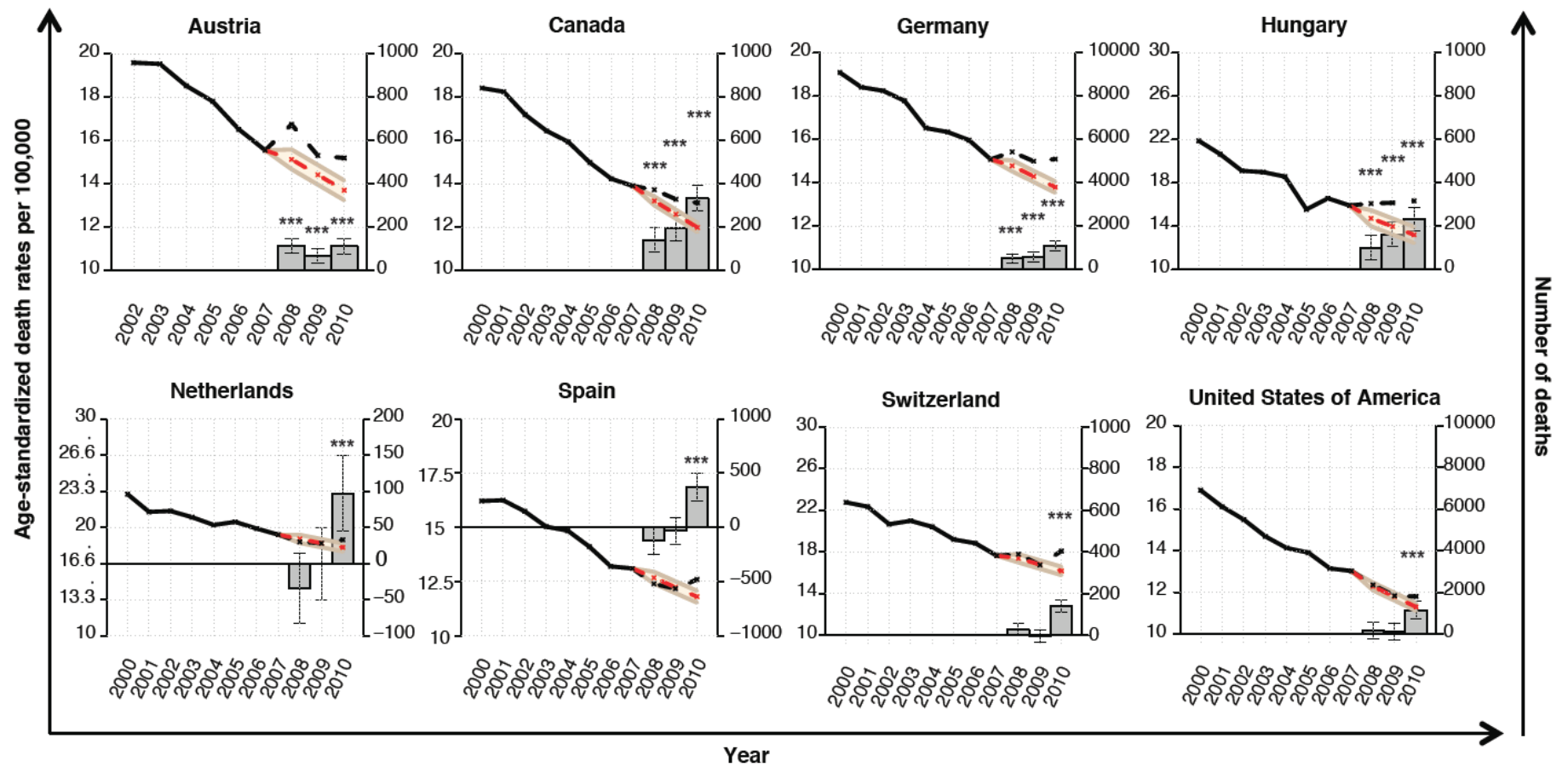

Figure 2. Time trend analysis of prostate cancer mortality. Time series analysis was used to assess whether actual prostate cancer mortality rates (left-hand y-axis) in 2008-2010 (black dotted line) differed from the projected rates (red dotted line) using the actual rates in 2000-2007 as an observation base (black continuous line). The estimated numbers of deaths (right-hand y-axis) resulting from this deviation (above 0 ) or saved (below 0 ) are shown as bars for 2008, 2009, and 2010. Error bars denote confidence intervals. ${ }^{* * *} p<0.001$.

\section{Strengths and weaknesses of the study}

Most commentators have studied socioeconomic inequalities, but not unemployment as a specific marker of unrest [4]. Few previous ecological studies have looked specifically at the association between changes in unemployment and cancer mortality rates. A major strength of this study is that it provides evidence for an association between a specific marker of economic crisis and a specific disease.

This study robustly demonstrated macroscopic trends in prostate cancer and unemployment in the OECD countries over a 20-year period. Data used were from a high-quality, centralised, objective database, which helped avoid selection and recall bias. The volume of data analysed allows for high statistical power and multiple robustness checks, bolstering confidence in the results obtained. Notably, our study used a conservative, fixed-effects regression analysis model. This model together with the implemented robustness checks account for many of the criticisms levelled at some of the first studies looking at the relationship between health outcomes and unemployment. Specifically, we controlled for time-invariant heterogeneity between countries; something that an aggregate time-series analyses failed to do. However, the retrospective observational study design is intrinsically prone to confoundment and bias. It is not possible to control for all possible co-dependent variables because the aetiology of prostate cancer still remains unknown. Thus, we accept that the association found in this study does not confirm causality.

It is plausible that an increase in prostate cancer for whatever reason is causing a rise in unemployment. However, given the magnitude of the unemployment increase and the relatively low unemployment rates for prostate cancer survivors compared to other cancers, this seems an unlikely explanation for our findings [30,31]. Multiple studies have demonstrated regional and racial variation in prostate cancer mortality 
$[32,33]$. The present study was only able to analyse trends in whole countries and in time periods of a year. Thus, we may have missed important variations at a regional intra-country level and over a shorter time-frame. The fact that we could not distinguish between different socioeconomic groups and ethnic groups is also a weakness, as we were unable to analyse whether the same groups who experience the largest increase in prostate cancer mortality are also the hardest hit by unemployment during the recession. Individual level socioeconomic data linked with prostate cancer data were not available. We were also unable to examine the extent to which access to prostate cancer screening, tumour stage at diagnosis, and aggressive treatment affected mortality in our study population, although these can be inferred from existing literature [34-36].

\section{Possible explanations}

Although the mechanism by which unemployment may increase prostate cancer mortality is not well understood, it is likely that reduced access to prompt diagnosis and treatment in less affluent populations largely explains the discrepancy in short-term prostate cancer mortality. Reduced access to timely diagnosis may well engender a reduction in the proportion of treatable prostate cancer cases. Indeed, the related but converse effect of sharp rises in the incidence of prostate cancer-observed as a consequence of the implementation of screening programmes to detect early cases-was demonstrated in the European Randomised Study of Screening for Prostate Cancer (ERSPC) to be associated with a $21 \%$ reduction in mortality [37].

As alluded to above, stage at diagnosis is an important prognostic indicator for all tumour types, and the diagnosis of late stage prostate cancer in lower SES groups contributes to the excess mortality in this group [38, 39]. Conversely, higher SES men tend to have lower tumour grades at diagnosis, supporting the hypothesis that the more favourable outcomes of this group are because of access to screening [34]. However, the mortality gap between lower and higher SES groups persists at different Gleason scores, suggesting that baseline tumour characteristics do not wholly explain the differing survival rates [36, 40]. The remainder of the mortality gap may be explained by access to treatment, which is well-documented to be associated with wealth in the US, where low SES is an independent predictor of management by 'watchful waiting' rather than radiotherapy or prostatectomy [38, 41]. This is not entirely explained by the cost of private health care, as differences in quality of care for prostate cancer accessed persist even in countries with health care systems dominated by public-sector funding and service provision, such as Sweden and the UK [40, 42-44].

Although the age at diagnosis is decreasing, the mean age of prostate cancer diagnosis is $72-74$ years and only $1 \%$ of cases are diagnosed younger than 50 years $[45,46]$. As such, the majority of men with a prostate cancer diagnosis must have already retired, so unemployment might be expected to have relatively little impact on the outcomes from this cancer. Prostate carcinoma is found on autopsy in most men aged 85 years [47] so it is possible that the apparent increase in deaths attributed to prostate cancer may be because of an increase in all-cause mortality with prostate cancer as a comorbidity. A weakness of the present study is the inability to analyse the effect of comorbid illness on the relationship.

Racial differences in prostate cancer mortality have been well-documented $[7,48,49]$, and it is difficult to separate the risks of black and minority ethnic groups from those of low SES groups [35]. These groups are also significantly more likely than white men to be unemployed $[50,51]$ and less likely to receive early diagnosis and aggressive treatment for prostate cancer [52]. Importantly, there is no difference in prostate cancer baseline disease characteristics or mortality between black and white men in equal-access healthcare systems in the US and the UK [53,54], suggesting that observed racial differences in other health care systems are because of inequalities of care rather than biological factors.

Diet and body fat are thought to play a role in prostate cancer aetiology, and both are likely to change in times of economic hardship. We controlled for lack of nutrition but not for obesity, which may be a common risk factor for prostate cancer and unemployment [55-58]. Research findings on nutritional factors in prostate cancer have been inconsistent, perhaps because of the lack of differentiation between localised and aggressive subtypes of prostate cancer [59,60]. Although lifestyle factors such as tobacco and alcohol consumption may contribute to prostate cancer mortality in association with lower SES, previous studies have found that the association is with lifetime consumption rather than current intake so these are unlikely to account for the increased mortality on the relatively short timescale studied here [61-63]. 
Previous studies have examined the effect of occupation on prostate cancer risk but not lack of employment. In a Dutch prospective study, only policemen had a slightly increased risk compared to the general population, and most occupations had no association with prostate cancer when controlling for potential confounding factors such as age, family history, smoking status, and diet [64]. Physical activity at work has been observed to be inversely associated with prostate cancer risk in lower SES men [65]. A study by Morris and colleagues in 1994 found that even relatively privileged people who retired early for reasons other than ill health had a significant mortality hazard compared to those who remained continuously in work. Further research on the type of work performed before unemployment may help to illuminate whether specific occupations are protective against prostate cancer.

\section{Implications and future directions}

This study has important ramifications for clinicians, researchers, and policymakers. Clinicians need to be conscious of the higher mortality in the unemployed and be aware of the bias towards conservatively managing prostate cancer patients of lower SES [66]. Research on the comparative effectiveness of different treatment strategies on localised and advanced prostate cancer is needed to guide clinical decisionmaking. Public health measures to improve early detection and treatment of prostate cancer in unemployed men are needed to reduce health inequalities in OECD countries. Although meta-analyses have not confirmed the value of prostate cancer screening programmes [67], others including the ERSPC study in which prostate cancer mortality reduced by $21 \%$ in the screening group of men aged $55-69$ years [37], do provide some support for such programmes. A targeted programme for unemployed and low SES men in this age group could help to reduce the burden of mortality observed in this study.

It is important for policymakers to consider the public health implications of economic austerity measures that lead to a rise in unemployment. Given that unemployment is not forecast to return to pre-recession levels in some OECD countries for several years, specific policies preventing further job losses and supporting return-to-work may improve cancer survival [68, 69]. Our work adds to the body of evidence on the problems that unemployment entails, and further work is warranted to analyse the effects of unemployment on health-related quality of life $[48,70]$ as well as mortality.

\section{Conclusions}

The 2008 recession led to a rapid decline in the GDP of many member countries of the OECD, the economies of many of which have yet to recover. This event has raised the question of how macroeconomic variations may impact cancer outcomes. Our study has shown that increases in aggregate unemployment are associated with significantly worse prostate cancer mortality in OECD countries. Our study may thus be seen as a first examination of the important prostate cancer-related consequences of the economic crisis.

\section{List of Abbreviations}

Cl confidence interval

ERSPC European Randomised Study of Screening for Prostate Cancer

GDP gross domestic product

ICD-10 International Classification of Diseases version 10

OECD Organisation for Economic Co-operation and Development

PSA prostate-specific antigen

SES Socioeconomic status

WHO World Health Organisation 


\section{Conflict of interest}

The authors declare that they have no conflict of interest.

\section{References}

1. OECD 2011 Health at a Glance 2011: OECD Indicators (OECD Publishing 2011)

2. Grönberg H (2003) Prostate cancer epidemiology Lancet 361(9360) 859-864 DOI: 10.1016/S0140-6736(03)12713-4 PMID: $\underline{12642065}$

3. Holmberg L and Van Hemelrijck M (2014) Recent results in cancer research. Fortschritte der Krebsforschung. Progrès dans les recherches sur le cancer 2014 vol 202 pp 1-7 PMID: 24531772

4. Gilligan T (2005) Social disparities and prostate cancer: mapping the gaps in our knowledge Cancer Causes Control 16(1) 45-53 DOI: $10.1007 /$ s10552-004-1291-x PMID: 15750857

5. Rundle A et al (2013) A prospective study of socioeconomic status, prostate cancer screening and incidence among men at high risk for prostate cancer Cancer Causes Control 24(2) 297-303 DOI: 10.1007/s10552-012-0108-6 PMCID: 3557724

6. Cheng I et al (2009) Socioeconomic status and prostate cancer incidence and mortality rates among the diverse population of California Cancer Causes Control 20(8) 1431-40 DOI: 10.1007/s10552-009-9369-0 PMID: 19526319 PMCID: 2746891

7. Du XL et al (2006) Racial disparity and socioeconomic status in association with survival in older men with local/regional stage prostate carcinoma: findings from a large community-based cohort Cancer 106(6) 1276-85 DOI: 10.1002/cncr.21732 PMID: 16475208

8. Rapiti E et al (2009) Impact of socioeconomic status on prostate cancer diagnosis, treatment, and prognosis Cancer 115(23) 5556-65 DOI: 10.1002/cncr.24607 PMID: 19787636

9. McKee M et al (2012) Austerity: a failed experiment on the people of Europe Clin Med 12(6) 346-50 DOI: 10.7861/clinmedicine.124-346 PMID: 22930881

10. David Stuckler and Sanjay Basu (2013) The Body Economic: Why Austerity Kills (Basic Books First Edit 2013)

11. Limb M (2012) Austerity measures will lead to rise in unemployment and suicides, says Marmot BMJ 344 e2887-e2887 DOI: 10.1136/bmj.e2887 PMID: 22522709

12. World Bank World Bank Development Indicators (2013) (available at http://data.worldbank.org/data-catalog/world-development-indicators)

13. Barr B et al (2012) Suicides associated with the 2008-10 economic recession in England: time trend analysis BMJ 345 e5142

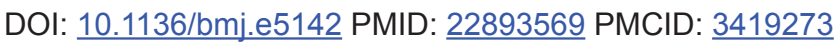

14. Chang SS et al Impact of $\mathbf{2 0 0 8}$ global economic crisis on suicide: time trend study in $\mathbf{5 4}$ countries Br Med J $52391-15$

15. Horton R (2009) The global financial crisis: an acute threat to health Lancet 373(9661) 355-6 DOI: 10.1016/S0140-6736(09) 60116-1 PMID: 19186260

16. Karanikolos M et al (2013) Financial crisis, austerity, and health in Europe Lancet 381(9874) 1323-31 DOI: 10.1016/S0140$\underline{6736(13) 60102-6}$ PMID: 23541059

17. Kentikelenis A et al (2011) Health effects of financial crisis: omens of a Greek tragedy Lancet 378(9801) 1457-8 DOI: 10.1016/ S0140-6736(11)61556-0 PMID: 21988763 
18. Stuckler D et al (2011) Effects of the 2008 recession on health: a first look at European data Lancet 378(9786) 124-5 DOI: 10.1016/S0140-6736(11)61079-9 PMID: 21742166

19. Davalos ME and French MT This recession is wearing me out! Health-related quality of life and economic downturns $J$ Ment Health Policy Econ 14(2) 61-72 PMID: 21881162

20. Morris JK, Cook DG and Shaper AG (1994) Loss of employment and mortality BMJ 308(6937) 1135-9 DOI: 10.1136/bmj.308.6937. 1135 PMID: 8173455 PMCID: 2540120

21. Roelfs DJ et al (2011) Losing life and livelihood: a systematic review and meta-analysis of unemployment and all-cause mortality Soc Sci Med 72(6) 840-54 DOI: 10.1016/j.socscimed.2011.01.005 PMID: 21330027 PMCID: 3070776

22. World Health Organization, Mortality database (2013) (available at http://apps.who.int/healthinfo/statistics/mortality/whodpms)

23. Mathers CD et al (2005) Counting the dead and what they died from: an assessment of the global status of cause of death data Bull World Health Organ 83(3) 171-7 PMID: 15798840 PMCID: 2624200

24. Cook RD and Weisberg S (1983) Diagnostics for heteroscedasticity in regression Biometrika 70 1-10 DOI: 10.1093/biomet/70.1.1

25. Davidson R and MacKinnon J (1993) Estimation and Inference in Econometrics (Oxford University Press, USA, New York City, USA, 1993)

26. Stuckler $\mathrm{D}$ et al (2009) The public health effect of economic crises and alternative policy responses in Europe: an empirical analysis Lancet 374(9686) 315-23 DOI: 10.1016/S0140-6736(09)61124-7 PMID: 19589588

27. Stuckler $D$ et al (2008) Mass incarceration can explain population increases in TB and multidrug-resistant TB in European and central Asian countries Proc Natl Acad Sci USA 105(36) 13280-5 DOI: 10.1073/pnas.0801200105 PMID: 18728189 PMCID: $\underline{2533181}$

28. Saffer $\mathrm{H}$ and Chaloupka $\mathrm{F}(2000)$ The effect of tobacco advertising bans on tobacco consumption $J$ Health Econ 19(6) 1117-37 DOI: $10.1016 /$ S0167-6296(00)00054-0

29. Dyba T, Hakulinen T and Päivärinta L (1997) A simple non-linear model in incidence prediction Stat Med 16(20) 2297-309 PMID: $\underline{9351166}$

30. National Cancer Registry/Northern Ireland Cancer Registry, All-Ireland Cancer Atlas 1995-1997 (2011)

31. De Boer AG et al Verbeek cancer survivors and unemployment: a meta-analysis and meta-regression JAMA J Am Med Assoc 301(7) 753-62

32. Cooperberg MR, Broering JM and Carroll PR (2010) Time trends and local variation in primary treatment of localized prostate cancer J Clin Oncol Off J Am Soc Clin Oncol 28(7) 1117-23 DOI: 10.1200/JCO.2009.26.0133

33. Wan N, Zhan FB and Cai Z (2011) Socioeconomic disparities in prostate cancer mortality and the impact of geographic scale South Med J 104(8) 553-9 PMID: 21886062

34. Shafique K, Oliphant R and Morrison DS (2012) The impact of socio-economic circumstances on overall and grade-specific prostate cancer incidence: a population-based study Br J Cancer 107(3) 575-82 DOI: 10.1038/bjc.2012.289

35. Chu DI and Freedland SJ (2010) Prostate cancer. Socioeconomic status and disparities in treatment patterns Nat Rev Urol 7(9) 480-1 DOI: $\underline{10.1038 / \text { nrurol.2010.121 PMID: } 20818323}$

36. Shafique K and Morrison DS (2013) Socio-economic inequalities in survival of patients with prostate cancer: role of age and Gleason grade at diagnosis PLoS One 8(2) e56184 DOI: 10.1371/journal.pone.0056184 PMID: 23418534 PMCID: $\underline{3571964}$ 
37. Schröder FH et al (2012) Prostate-cancer mortality at 11 years of follow-up N Engl J Med 366(11) 981-90 DOI: 10.1056/NEJMoa1113135 PMID: 22417251

38. Gopal K Singh et al Area Socioeconomic Variations in US Cancer Incidence, Mortality, Stage, Treatment, and Survival, 1975-1999 (Bethseda, MD: National Cancer Institute, 2003)

39. Marlow NM et al (2010) Disparities associated with advanced prostate cancer stage at diagnosis $J$ Health Care Poor Underserved 21(1) 112-31 DOI: $\underline{10.1353 / h p u .0 .0253}$ PMID: 20173259

40. Lyratzopoulos $\mathrm{G}$ et al Population based time trends and socioeconomic variation in use of radiotherapy and radical surgery for prostate cancer in a UK region: continuous survey BMJ 340 c1928 PMID: 20413566 PMCID: 2858795

41. Krupski TL et al (2005) Geographic and Socioeconomic Variation in the Treatment of Prostate Cancer J Clin Onco 23(31) 7881-8 DOI: $\underline{10.1200 / J C O .2005 .08 .755}$

42. Berglund $\mathrm{A}$ et al (2012) Differences according to socioeconomic status in the management and mortality in men with high risk prostate cancer Eur J Cancer Oxford, Engl 48(1) 75-84 DOI: 10.1016/j.ejca.2011.07.009

43. Li X et al (2012) Neighborhood deprivation and prostate cancer mortality: a multilevel analysis from Sweden Prostate Cancer Prostatic Dis 15(2) 128-34 DOI: 10.1038/pcan.2011.46

44. McVey GP et al (2010) Initial management of low-risk localized prostate cancer in the UK: analysis of the British Association of Urological Surgeons Cancer Registry BJU Int 106(8) 1161-4 DOI: 10.1111/j.1464-410X.2010.09288.x PMID: 20456339

45. National Cancer Institute (2013) "SEER Cancer Statistics Review, 1975-2010"

46. Cancer Research UK (2013) Prostate cancer incidence statistics

47. Sakr WA et al (1993) The frequency of carcinoma and intraepithelial neoplasia of the prostate in young male patients $J$ Urol 150 379-85 PMID: $\underline{8326560}$

48. Barocas DA and Penson DF (2010) Racial variation in the pattern and quality of care for prostate cancer in the USA: mind the gap BJU Int 106(3) 322-8 DOI: 10.1111/j.1464-410X.2010.09467.x PMID: 20553251 PMCID: 2910169

49. Schwartz K et al (2009) Interplay of Race, Socioeconomic Status and Treatment on Survival of Prostate Cancer Patients Urology 74(6) 1296-302 DOI: 10.1016/j.urology.2009.02.058 PMID: 19962532 PMCID: 2791874

50. Bureau of Labor Statistics (2009) "The Employment Situation"

51. Bell D and Blanchflower D (2009) What should be done about rising unemployment in the OECD? Inst Study Labor Discuss Pap

52. Shavers VL et al (2004) Race/ethnicity and the receipt of watchful waiting for the initial management of prostate cancer $J$ Gen Intern Med 19(2) 146-55 DOI: 10.1111/j.1525-1497.2004.30209.x PMID: 15009794 PMCID: 1492143

53. Evans $S$ et al (2010) Clinical presentation and initial management of black men and white men with prostate cancer in the United Kingdom: the PROCESS cohort study Br J Cancer 102(2) 249-54 DOI: 10.1038/sj.bjc.6605461 PMCID: 2816646

54. Graham-Steed T et al (2013) "Race" and prostate cancer mortality in equal-access healthcare systems Am J Med 126(12) 1084-8 DOI: 10.1016/j.amjmed.2013.08.012 PMID: 24262722 PMCID: 4100601

55. Allott EH, Masko EM and Freedland SJ (2013) Obesity and prostate cancer: weighing the evidence Eur Urol 63(5) 800-9 DOI: 10.1016/j.eururo.2012.11.013 PMCID: 3597763

56. Greve J (2008) Obesity and labor market outcomes in Denmark Econ Hum Biol 6(3) 350-62 DOI: 10.1016/j.ehb.2008.09.001 PMID: 18993121 
57. Johansson E et al (2009) Obesity and labour market success in Finland: the difference between having a high BMI and being fat Econ Hum Biol 7(1) 36-45 DOI: 10.1016/j.ehb.2009.01.008 PMID: 19249259

58. Robroek SJ et al (2013) The contribution of overweight, obesity, and lack of physical activity to exit from paid employment: a meta-analysis Scand J Work Environ Health 39(3) 233-40 DOI: 10.5271/sjweh.3354 PMID: 23460255

59. Discacciati A and Wolk A (2014) Lifestyle and dietary factors in prostate cancer prevention Recent Results Cancer Re 202 27-37 DOI: $10.1007 / 978-3-642-45195-9$ _ 3

60. Park SY et al (2007) Fat and meat intake and prostate cancer risk: the multiethnic cohort study Int J Cancer 121(6) 1339-45 DOI: $\underline{10.1002 / \mathrm{jjc} .22805}$ PMID: $\underline{17487838}$

61. McGregor SE et al (2013) Case-control study of lifetime alcohol intake and prostate cancer risk Cancer Causes Control 24 451-61 DOI: 10.1007/s10552-012-0131-7

62. Murphy AB et al (2013) Smoking and prostate cancer in a multi-ethnic cohort Prostate 73(14) 1518-28 DOI: 10.1002/pros.22699 PMID: 23824512 PMCID: $\underline{3931574}$

63. Schoonen WM et al (2005) Alcohol consumption and risk of prostate cancer in middle-aged men Int J Cancer 113(1) 133-40 DOI: $10.1002 /$ ijc. 20528

64. Zeegers MPA et al (2004) A prospective study of occupation and prostate cancer risk J Occup Environ Med 46(3) 271-9 DOI: 10.1097/01.jom.0000116961.48464.6b PMID: 15091290

65. Pierotti B et al (2005) Lifetime physical activity and prostate cancer risk Int J Cancer 114(4) 639-42 DOI: 10.1002/ijc.20783

66. Rayford W (2006) Managing the low-socioeconomic-status prostate cancer patient $J$ Natl Med Assoc 98(4) 521-30 PMID: 16623064 PMCID: 2569254

67. Ilic D et al (2013) Screening for prostate cancer Cochrane Database Syst Rev 1 CD004720 DOI: 10.1002/14651858.CD004720. pub3 PMID: 23440794

68. Congress of the United States Congressional Budget Office An Update to the Budget and Economic Outlook: Fiscal Years 2012 to $2022(2012)$

69. UK Office for Budget Responsibility Economic and fiscal outlook (The Stationery Office London UK 2013)

70. Penson DF et al (2001) The association between socioeconomic status, health insurance coverage, and quality of life in men with prostate cancer J Clin Epidemiol 54(4) 350-8 DOI: 10.1016/S0895-4356(00)00312-7 PMID: 11297885 